\title{
Changes in Air Temperatures on Mount Fuji, Japan
}

\author{
Noriko Sakano, Nobuyuki Miyatake*, Shoko Murakami \\ Department of Hygiene, Faculty of Medicine, Kagawa University, Miki, Kagawa, Japan \\ E-mail: *miyarin@med.kagawa-u.ac.jp \\ Received August 2, 2011; revised September 16, 2011; accepted September 25, 2011
}

\begin{abstract}
The changes in air temperatures on Mount (Mt.) Fuji, Japan were evaluated. Various parameters of air temperatures on Mt. Fuji in Japan were obtained from Japan Metrological Agency. Parameters of air temperatures were positively correlated with years on Mt. Fuji. In addition, the number of days under $-24^{\circ} \mathrm{C}$ in January was negatively correlated with years. Global warming was also proved on Mt. Fuji in Japan, especially in winter. Therefore, we need to deal with global warming effect.
\end{abstract}

Keywords: Air Temperature, Mount Fuji, Global Warming

\section{Introduction}

Global average temperatures are predicted to increase by the end of this century. An increase in mortality related to heat waves has been reported from various industrialized countries [1]. We have showed that higher air temperature was closely associated with higher ambulance transports in Takamatsu [2] and Okayama [3] areas, Japan. In addition, we have also reported that positive changes in air temperatures were noted in some Japanese areas $[4,5]$. However, global warming was not proved at Showa base in Antarctica. In addition, the number of days of over $4^{\circ} \mathrm{C}$ in January was negatively correlated with years $(r=-0.427, p=0.0053)$ [6]. Therefore, whether an increase in air temperatures is actually increasing in the world remains to be investigated. Mount (Mt.) Fuji (3775.63 m) is the highest mountain in Japan and the parameters of air temperatures have been monitored. Therefore, we evaluated the chronological changes in air temperatures on Mt. Fuji, Japan.

\section{Methods}

Daily air temperatures at a meteorological observatory on Mt. Fuji (1965-2009) were obtained from Japan Meteorological Agency [7]. A meteorological observatory on Mt. Fuji is located almost top of the mountain. Mean air temperature, mean of the highest air temperatures and mean of the lowest air temperatures in January, August and a year were used for analysis. Daily data of air temperature in August, 1970 were could not obtain. In addition, the changes in the number of days under various air temperatures in January and those over various air temperatures in August were also used for analysis.

Simple correlation analysis was used to test the significance of the linear relationship among continuous variables: $p<0.05$ was considered to be statistically significant.

\section{Results}

Mean air temperature, mean of the highest air temperatures and mean of the lowest air temperatures in a year on Mt. Fuji were significantly correlated with years (mean air temperature in a year: $\mathrm{r}=0.500, p=0.0005$ ) (Table 1 , Figure 1). From single regression line, estimated positive change in mean air temperature in a year for 50 years was corresponded to $1.3^{\circ} \mathrm{C}$ on Mt. Fuji, Japan.

In addition, the relation between years and the number of days over various air temperatures in August, and between years and the number of days under various air temperatures in January were also evaluated. The number of days of under $-24^{\circ} \mathrm{C}$ in January was negatively correlated with years (Table 2, Figure 2). However, the number of days over various air temperatures was not correlated with years in August.

\section{Discussion}

Although global warming was not proved at Showa base in Antarctica [6], clinical impact of global warming effect on Mt. Fuji was noted in this study. Especially, the number of days under $-24^{\circ} \mathrm{C}$ in January was significantly reduced. Bai et al. showed that the number of unusual 
Table 1. Relationship between parameters of air temperature and years on Mt. Fuji (1965-2009).

\begin{tabular}{|c|c|c|c|c|c|c|}
\hline & \multicolumn{2}{|c|}{ January } & \multicolumn{2}{|c|}{ August } & \multicolumn{2}{|c|}{ Year } \\
\hline & $\mathrm{r}$ & $p$ & $\mathrm{r}$ & $p$ & $\mathrm{r}$ & $p$ \\
\hline Mean air temperature & 0.213 & 0.1594 & 0.193 & 0.2104 & 0.500 & 0.0005 \\
\hline Mean of the highest air temperature & 0.170 & 0.2649 & 0.110 & 0.4772 & 0.374 & 0.0124 \\
\hline Mean of the lowest air temperature & 0.229 & 0.1310 & 0.259 & 0.0899 & 0.381 & 0.0108 \\
\hline
\end{tabular}

Table 2. Relationship between years and various levels of temperature in January and August on Mt. Fuji.

\begin{tabular}{cccccc}
\hline & January & & \multicolumn{2}{c}{ August } \\
\hline & $\mathrm{r}$ & $p$ & & $\mathrm{r}$ & $p$ \\
$\leq-21^{\circ} \mathrm{C}$ & -0.188 & 0.2163 & $8^{\circ} \mathrm{C} \leq$ & 0.064 & 0.6817 \\
$\leq-22^{\circ} \mathrm{C}$ & -0.192 & 0.2056 & $9^{\circ} \mathrm{C} \leq$ & 0.016 & 0.9160 \\
$\leq-23^{\circ} \mathrm{C}$ & -0.272 & 0.0710 & $10^{\circ} \mathrm{C} \leq$ & -0.113 & 0.4665 \\
$\leq-24^{\circ} \mathrm{C}$ & -0.336 & $\mathbf{0 . 0 2 3 9}$ & $11^{\circ} \mathrm{C} \leq$ & 0.008 & 0.9577 \\
$\leq-25^{\circ} \mathrm{C}$ & -0.328 & $\mathbf{0 . 0 2 7 6}$ & $12^{\circ} \mathrm{C} \leq$ & 0.064 & 0.6671 \\
\hline
\end{tabular}

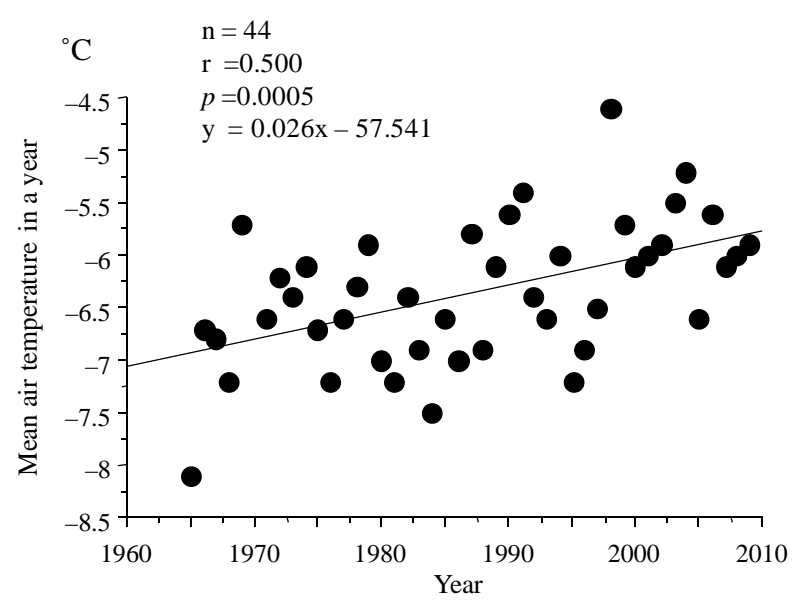

Figure 1. Simple correlation analysis between mean air temperature in a year and years on Mt. Fuji (1965-2009).

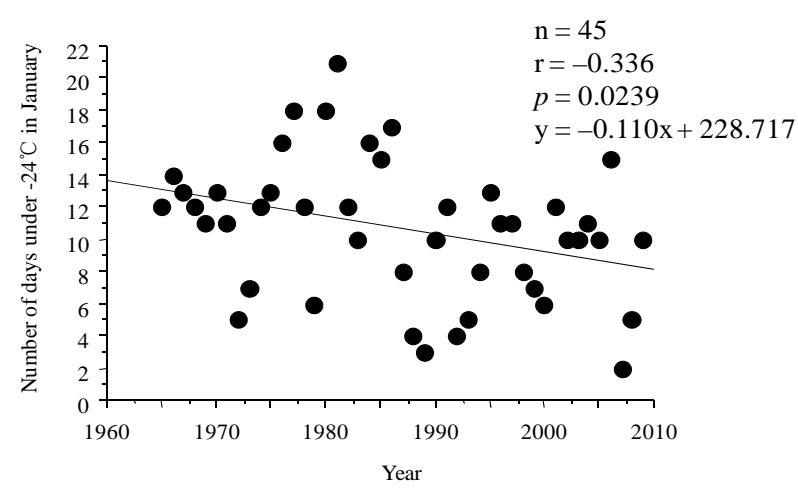

Figure 2 Simple correlation analysis between the number of days under $-24^{\circ} \mathrm{C}$ in January and years on Mt. Fuji (1965-2009).

deaths in the summer of 1994 in Osaka, Japan was more compared to those of previous years [7]. Qiu et al. also reported that an unusually hot spell in 1999 was followed by a high mortality rate in Hokkaido, Japan [8]. The world may be a very different place today than it was only a short period ago. Also in Japan, urbanization and industrialization seems to be accelerated.

In conclusion, in this study, the evidence of global warming was also proved on Mt. Fuji, especially in winter, which is the highest mountain in Japan. Therefore, it seems reasonable to suggest that simply dealing with global warming effect i.e. innovation of the thermal energy metabolism in cities and individual coping with high air temperatures is urgently required in Japan.

\section{Acknowledgements}

This research was supported in part by Research Grants from Fukutake Science and Culture Foundation, Japan.

\section{References}

[1] M. Lye, A. Kamal, "Effects of a Heatwave on Mortality-Rates in Elderly Inpatients," Lancet, Vol. 309, No. 8010, 1977, pp. 529-531. doi:10.1016/S0140-6736(77)91385-X

[2] N. Miyatake, M. Nakao, N. Sakano, S. Suna, T. Suzue and T. Hirao, "Higher Temperatures Were Closely Associated with Higher Ambulance Transports in Takamatsu Area, Japan,” Journal of Environmental Protection, Vol. 2, No. 1, 2011, pp. 72-75. doi:10.4236/jep.2011.21007

[3] N. Sakano, N. Miyatake, T. Suzue, S. Suna, T. Hirao and K. Ogino, "The Relation between High Temperatures and Ambulance Transports in Okayama City, Japan,” American Journal of Preventive Medicine, Vol. 6, No. 1, 2011, pp. 17-20.

[4] N. Miyatake, N. Sakano, S. Murakami, S. Suna, T. Suzue 
and T. Hirao, "Comparison of the Changes in Temperatures among Rural, Urban and Metropolitan Areas around the Inrand Sea, Japan,” Environ Monit Assess, Vol. 181, No.1-4, 2011, pp. 525-530.

[5] N. Sakano, N. Miyatake, S. Murakami, T. Suzue, T. Hirao and K. Ogino, "Changes in Temperatures in Okayama Area Compared with Different Urbanization Areas, Japan,” Journal of Environmental Protection, Vol. 2, No. 2, 2011, pp. 162-167. doi:10.4236/jep.2011.22018

[6] N. Miyatake, N. Sakano, S. Murakami, T. Suzue and T.
Hirao, "Global Warming Was Not Proved at Showa Base in Antarctica,” Journal of Environmental Protection, Vol. 2, No. 3, 2011, pp. 323-325. doi:10.4236/jep.2011.23036

[7] Japan Meteorological Agency, 2010. http://www.data.jma.go.jp/obd/stats/etrn/index

[8] D. Qiu, T. Tanihata, H. Aoyama, T. Fujita, Y. Inaba and M. Minowa, "Relationship between a High Mortality Rate and Extreme Heat during the Summer of 1999 in Hokkaido Prefecture, Japan,” Journal of Epidemiology, Vol. 12, No. 3, 2002, pp. 254-257. 